\title{
Starr-Edwards aortic valve: Forty-four years old and still working!
}

\author{
Pankaj Saxena, FRACS, PhD, ${ }^{\mathrm{a}}$ Crystal R. Bonnichsen, MD, ${ }^{\mathrm{b}}$ and Kevin L. Greason, MD, ${ }^{\mathrm{a}}$ Rochester, Minn
}

The Starr-Edwards valve (Edwards Lifesciences, Irvine, Calif) was first introduced in clinical practice approximately 50 years ago. ${ }^{1}$ Since then, more than 200,000 implants of this valve have been performed worldwide. ${ }^{2}$ We highlight the durability of the valve in this case report of a patient with a functioning Starr-Edwards aortic valve implanted more than 44 years ago.

\section{CLINICAL SUMMARY}

A 66-year-old man presented to the Mayo Clinic with a 7-cm ascending aortic aneurysm and symptomatic 2-vessel coronary artery disease (Figure 1, $A$ and $B$ ). The patient previously had total correction of tetralogy of Fallot and aortic valve replacement with a 26-mm Starr-Edwards valve at 22 years of age at the Mayo Clinic. During the current evaluation, echocardiography demonstrated an ejection fraction of $45 \%$, a mean systolic Doppler gradient across the valve prosthesis of $30 \mathrm{~mm} \mathrm{Hg}$, and mild to moderate prosthetic valvular regurgitation (Figure 1, C).

The patient underwent a successful operation that included redo sternotomy, bicaval and aortic cannulation, and myocardial protection with antegrade and retrograde cold blood cardioplegia. We performed coronary artery bypass graft revascularization to the left anterior descending and obtuse marginal coronary arteries, replacement of the

From the Division of Cardiovascular Surgery ${ }^{\mathrm{a}}$ and Cardiovascular Diseases, ${ }^{\mathrm{b}}$ Mayo Clinic, Rochester, Minn.

Disclosures: Authors have nothing to disclose with regard to commercial support.

Received for publication April 24, 2013; accepted for publication May 15, 2013; available ahead of print July 15, 2013.

Address for reprints: Kevin L. Greason, MD, Division of Cardiovascular Surgery, Mayo Clinic, 200 First Street SW, Rochester, MN 55905 (E-mail: greason. kevin@mayo.edu).

J Thorac Cardiovasc Surg 2013;146:e21-2

$0022-5223 / \$ 36.00$

Copyright (C) 2013 by The American Association for Thoracic Surgery

http://dx.doi.org/10.1016/j.jtcvs.2013.05.034

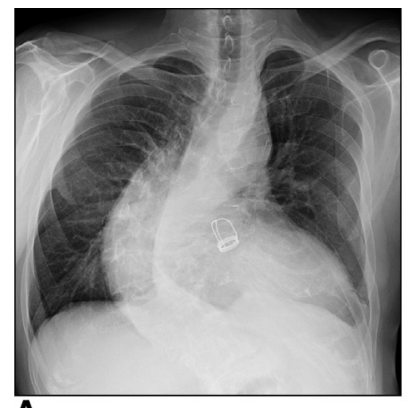

A

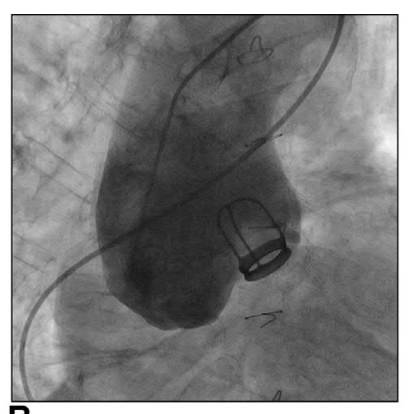

$\mathbf{B}$
Starr-Edwards valve with a composite valve conduit of a 25-mm Carbomedics Top-Hat valve (Sorin Group, Milan, Italy) and 30-mm polyester graft, and hemi-arch replacement of the aorta under deep hypothermic circulatory arrest.

Examination of the Star-Edwards valve demonstrated a mild degree of pannus growth over the sewing ring of the prosthetic valve (Figure 1, D) but no major structural valve deterioration. The patient had an uncomplicated postoperative course and was discharged on postoperative day number 5. Pathologic examination of the aorta showed cystic medial degeneration. The patient was in New York Heart Association functional class II at 5 weeks of follow-up with a normally functioning prosthetic valve.

\section{DISCUSSION}

Surgical treatment of heart valve disease was revolutionized by the introduction of the Starr-Edwards ball and cage valve model in the 1960s. Clinical follow-up of more than 30 years with this valve has been satisfactory..$^{2-4}$ Our patient was asymptomatic up to 1 year ago when he presented with angina. His most recent cardiovascular evaluation was 10 years before clinical presentation. There were no bleeding or thromboembolic complications related to his prosthetic aortic valve.

\section{CONCLUSIONS}

We report the 44-year follow-up of a patient who had aortic valve replacement with the Starr-Edwards valve without any significant valvular dysfunction or thromboembolic complications. Although Starr-Edwards valves have largely been replaced in clinical practice by other mechanical valves, they may still provide ultralong-term durability in patients who underwent operation in an earlier era.
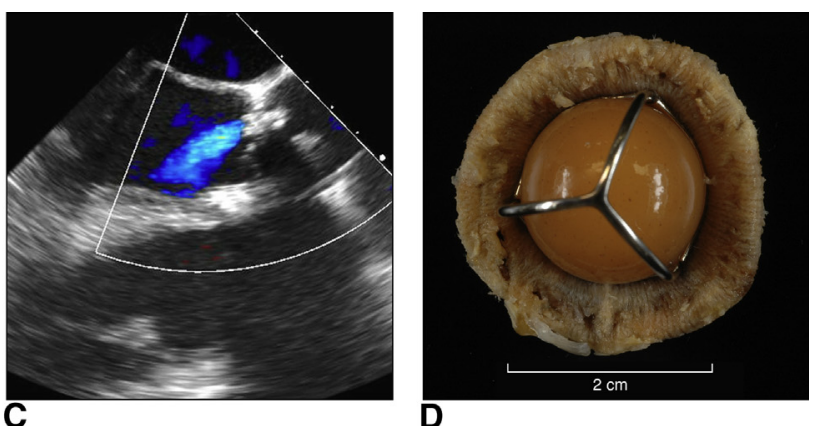

FIGURE 1. A, Chest X-ray (posterior-anterior) view shows Starr-Edwards valve (Edwards Lifesciences, Irvine, Calif) in aortic position. B, Aortogram shows large ascending aortic aneurysm. C, Intraoperative transesophageal echocardiogram in long axis with color Doppler shows mild regurgitation across the prosthetic aortic valve. D, Explanted valve prothesis from the aortic aspect with functional ball and cage mechanism. 


\section{References}

1. Starr A, Edwards ML. Mitral replacement: clinical experience with a ball-valve prosthesis. Ann Surg. 1961;154:726-40.

2. Godje OL, Fischlein T, Adelhard K, Nollert G, Klinner W, Reichart B. Thirty-year results of Starr-Edwards prostheses in the aortic and mitral position. Ann Thorac Surg. 1997;63:613-9.
3. He GW, Grunkemeier GL, Gately HL, Furnary AP, Starr A. Up to thirty-year survival after aortic valve replacement in the small aortic root. Ann Thorac Surg. 1995;59:1056-62.

4. Aludaat C, Gay A, Guetlin A, Nafeh-Bizet C, Bessou JP, Doguet F. Favorable evolution of a 43-year-old Starr-Edwards valve in the tricuspid position. J Heart Valve Dis. 2012;21:679-81.

\title{
A complicated case of Carney complex: Fifth reoperative cardiac surgery for resection of recurrent cardiac myxoma
}

\author{
Manuel Wilbring, MD, ${ }^{\mathrm{a}}$ Stephan Wiedemann, MD, ${ }^{\mathrm{b}}$ Utz Kappert, MD, ${ }^{\mathrm{a}}$ and Klaus Matschke, MD, \\ Dresden, Germany
}

Carney complex is a rare genetic disorder that was first described by Carney and colleagues ${ }^{1}$ in 1985 . It is mainly characterized by cardiac myxoma, spotty pigmentation and endocrine hyperactivity. In approximately $50 \%$ of the affected patients, a heterozygous mutation of the protein kinase A regulatory subunit 1 gene (PRKARIA) can be found. The mutation, which is usually localized on the long arm of chromosome 17 (17q22-q24), is named CC-Type 1. In CC-Type 2, the mutation can be found on chromosome 2 (2p16). The heredity is autosomal dominant with variable penetrance. There exist no clinical differences between genetic carriers and noncarriers. ${ }^{2}$

\section{CLINICAL SUMMARY}

In 2012, a 60-year-old female patient with Carney complex and history of previous 4 cardiac operations for recurrent myxoma was seen for elective echocardiographic control. The previous control by magnetic resonance imaging (MRI) 5 months previously had been unremarkable (Figure 1, A).

In 1988, 1991, 2002, and 2008 she had already undergone cardiac surgery for resection of cardiac myxoma at different localizations. Further clinical signs of Carney complex were recurrent mucosal tumors since her earliest childhood, spotty pigmentation, hirsutism, syndactyly of the toes, kyphosis, hyperthyroidism, and an adenoma of the pituitary gland. The patient also had a history of peripheral arterial

From the Departments of Cardiac Surgery ${ }^{\mathrm{a}}$ and Cardiology, ${ }^{\mathrm{b}}$ University Heart Center Dresden, Dresden, Germany.

Disclosures: Authors have nothing to disclose with regard to commercial support.

Received for publication May 26, 2013; accepted for publication May 31, 2013; available ahead of print July 17, 2013

Address for reprints: Manuel Wilbring, MD, Department of Cardiac Surgery, University Heart Center Dresden, Fetscherstrasse 76, 01307 Dresden, Germany (E-mail: manuel.wilbring@gmail.com).

J Thorac Cardiovasc Surg 2013;146:e22-4

$0022-5223 / \$ 36.00$

Copyright (c) 2013 by The American Association for Thoracic Surgery

http://dx.doi.org/10.1016/j.jtcvs.2013.05.016 embolism and occlusion of superficial femoral artery. As demonstrated in the family tree in Figure 2, the patient was the only one in her family affected by clinical signs of Carney complex. Genetic examination of her family has not been performed to date.

MRI and echocardiography revealed a new intracardiac tumor-formation in the left ventricle affecting the mitral annulus (Figure 1, $A-C$ ). Cardiac surgery was performed through a median sternotomy and with common aortic cannulation. For venous cannulation, a 2-stage cannula was used. The procedure was performed in normothermia. Intraoperatively, the myxoma was resected (Figure 1,D). Because of the involvement of the mitral annulus and the need for radical resection, biologic mitral valve replacement was also performed. The intraoperative and postoperative courses were uneventful. Predischarge echocardiography revealed good prosthetic function. Histopathologic examination identified the tumor as a myxoma. The patient was dismissed from the hospital on postoperative day 6 .

\section{DISCUSSION}

Carney complex is a rare genetic disorder. ${ }^{1,3}$ This patient demonstrated all the typical signs of Carney complex including myxoma, spotty pigmentation, endocrine hyperactivity, and cutaneous tumors. As is typical with complications of cardiac tumors, the patient also had a history of peripheral arterial embolism and occlusion of superficial femoral artery. In contrast with other reported cases, a specific characteristic of the present case was the fifth recurrence of myxoma, each time at a different location. ${ }^{4,5}$ The reported patient is the sole person affected by Carney complex in her family. This might be explained by the variable penetrance of the autosomal dominant genetic disorder. Her fifth reoperative cardiac surgical procedure could be performed without any procedural morbidity, despite strong pericardial adhesions. Worth mentioning is the fact that MRI control 